\title{
Readiness Analysis Patient Centered Care (PCC) in Child Department
}

\author{
Dea Amantha Azaria; Elsye Maria Rosa \\ Universitas Muhammadiyah Yogyakarta, Yogyakarta, Indonesian \\ http://dx.doi.org/10.18415/ijmmu.v9i2.3543
}

\begin{abstract}
At this time, public awareness about health is getting higher. According to www.kemenkes.go.id in 2019, Public Health Development Index (IPKM) nationally has increased in the last 5 years. This study aims to determine the difference before and after the implementation of Patient-Centered Care (PCC) at a Hospital in Central Java as a basis for assessing hospital readiness. This study was divided into two groups of patients, namely the treatment group and the control group. The two groups came from the same hospital of origin, the difference was only in the time of data collection. Both groups were given pre-test and post-test. Respondents from both the treatment group and the control group each amounted to 12 people for patients and for Child Care Professionals (PPA) using a saturated sample, where the population was also used as a sample. T-Test Independent Analysis results obtained the Asymp. Sig. (2tailed) value is $0.003(<0.05)$ so that conclusion is that there are differences in patient perceptions in the treatment group and control group before and after the implementation of Patient Center Care services on the children's part of a hospital in Central Java, so the alternative hypothesis is accepted.
\end{abstract}

Keywords: Patient-Centered Care (PCC); Hospital

\section{Introduction}

At this time, public awareness about health is getting higher. According to the ministry of health.go.id in 2019, nationally the Public Health Development Index (IPKM) has increased in the last 5 years. This index applies 30 health indicators which are grouped into 7 sub-indices, including Reproductive Health, Health Behavior, Non-Communicable Diseases, Infectious Diseases, Infant Health, Environmental Health, and Health Services. This situation cannot be separated from the important role of the Hospital which is the foremost service in the health sector. Hospital is a health effort facility that organizes health service activities and can function as a place for health education and research (Ministry of Health of the Republic of Indonesia, 1994:2). Then, Law Number 44 of 2009 states that the Hospital is a health service institution that provides complete individual health services that provide inpatient, outpatient, and emergency services.

The American Academy of Pediatrics (2012) states that to improve the quality of services in hospitals, not only address the patient's disease problems but family involvement is also prioritized in terms of making clinical decisions based on the information and collaborative processes, as well as conducting follow-up discussions with families about treatment plans. Next, so that it is more efficient 
and effective in treatment time and improves communication with the health team who handles these patients, satisfaction will arise in professional service to patients. To realize improvements in terms of service, namely the application of Patient-Centered Care (PCC).

Patient-Centered Care (PCC) is a new paradigm that must be applied in health services in Indonesia, placing the patient as the center of health care where there is a group that respects each other and is responsive to all the needs and values of individual patients, so that the dimensions of care are received by patients are respect, emotional support, physical comfort, information and communication, coordination in carrying out care, and involvement of patients and families in guiding clinical decision making to resolve the patient's problems.

Unfortunately, not all hospitals in Indonesia implement PCC in terms of services. Most of the hospitals that has not implemented PCC-based services in serving patients, especially in the pediatric section. A Hospital in Central Java still applies a one-way system, where one doctor on duty will visit each patient to check the patient's current condition without first communicating with other patient care providers. This needs attention because patients are considered necessary to get better services. The PCC system is considered to be able to improve the quality of hospital services in dealing with patients in terms of 1) Respecting patient choices and assessments, 2) Emotional support, 3) Physical comfort, 4) Information and education, 5) Continuity and transition, 6) Coordination of services, 7 ) Access to services and 8) Involve family and friends.

The hypothesis of this research is: There are differences in the perceptions of patients in the intervention group and the control group before and after the implementation of Patient Center Care services in the children's section in the children's section at a hospital in Central Java.

\section{Method}

\section{Participant Characteristics and Research Design}

In this study, the author uses a quantitative approach with experimental research. The type of research used in this study is a quasi-experimental research. The form of the quasi design used in this study is the nonequivalent control group design. This design is almost the same as the pretest-posttest control group design, but in this design both the experimental group and the control group are not chosen randomly.

Participant characteristic in this study were: 1) Child Care Professionals (PPA) at a Hospital in Central Java who became a companion for pediatric patients; and 2) Pediatric patients who were hospitalized in September 2020.

\section{Sampling Procedures}

The sampling technique that will be used in this study is a non-probability sampling technique, namely Purvosive Sampling for pediatric patients with inclusion criteria, namely patients with medical records who undergo hospitalization in the pediatric ward for at least 2 to 5 days at a Hospital in Central Java. Then for the PPA using a saturated sample sampling technique (all members of the population are sampled) for the PPA.

\section{Sample Size, Power, and Precision}

Determination of the number of PPA samples is 5 people's which consist of a doctor, a nurse, a pharmacy and 2 nutrition's. Then, the number of pediatric patients sample's, we used Slovin method which has the formula: 


$$
\mathrm{n}=\mathrm{N} /\left(1+\left(\mathrm{Nx} \mathrm{e}^{2}\right)\right)
$$

Where:

$\mathrm{n} \quad$ : number of minimum samples

$\mathrm{N}$ : number of poppulation

e : margin of error

The population in this study were 40 children's. After calculating, it is known that the sample required is 11.428 or as many as 12 children's.

\section{Measures and Covariates}

Patient Centered Care (PCC)

Patient Centered Care is a health care service in managing patients with mutual respect, and responsive to the choice of the needs of the patient's personal values and has taken into account all the values desired by the patient when making a clinical decision. The indicator that we used to measure PCC (Gerteis et al., 1993) are: a) Respecting the values, choices, and needs to be expressed by the patient, b) Coordination and integration of care, c) Information, communication, and education, d) Physical comfort, e) Emotional support and reducing fear and anxiety, f ) Involvement of family and friends, g) Continuing care and smooth transition and h) Access to services.

\section{Medical Records}

Medical Records is a written information regarding identity, history taking, physical examination, laboratory, diagnosis and all medical treatment services provided to patients who receive treatment services either inpatient, outpatient or in emergency services.

Data collection using a questionnaire. To measure the level of patient satisfaction, researchers used the State-Trait Anxiety Inventory (SAI) questionnaire which was adopted from Spielberger, C.D. (1983) with a Likert scale of 1-5. Then, to measure service points by Caregivers Professionals will use a questionnaire adopted from the instrument points in the PCC dimension from Gerteis et al. (1993) which consists of 1) Respecting the values, choices, and needs to be expressed by patients, 2) Coordination and integration of care, 3) Information, communication, and education, 4) Physical comfort, 5) Emotional support and reducing fear and anxiety, 6) Involvement of family and friends, 7) Continuing care and a smooth transition, and 8) Access to services with the Guttman scale. We used SPSS program to analyze data with T-Test Independent Analysis to get the conclusion of our hypothesis.

\section{Data Analysis}

The test of the difference between these two averages aims to determine whether there is a significant difference between the PPA and patient scores before and after PCC was applied and after PCC was applied. The test used is a two-party test, and the use of hypothesis analysis tests is determined after knowing the results of the normality test. If the data is normally distributed, the test used is the TTest Independent Analysis (correlated parametric statistics), if the data is not normally distributed, the Wilcoxon test (correlated non-parametric statistics) is used. 


\section{Results and Discussion}

\section{Univariate Test Analysis}

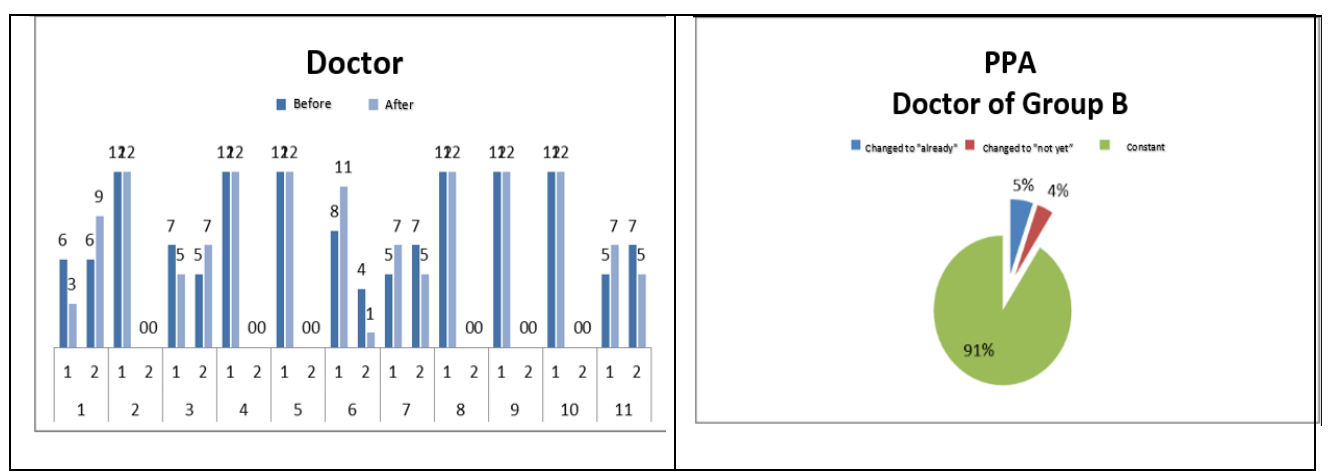

Figure 1. Changed Answer Control Group: PPA Doctor

In the doctor's PPA, there are $91 \%$ of patients think it is constant and $9 \%$ think it changes in answering the assessment of the doctor's treatment of the patient. Of the $9 \%$ of opinions that changed, $4 \%$ had an opinion that changed to "not yet" in the dimensions of respecting the values, preferences, and needs of patients as well as the dimensions of continuing care and a smooth transition. Then, 5\% of respondents have an opinion changed to "already" on the dimensions of communication and education, dimensions of physical comfort, and dimensions of access to health services.

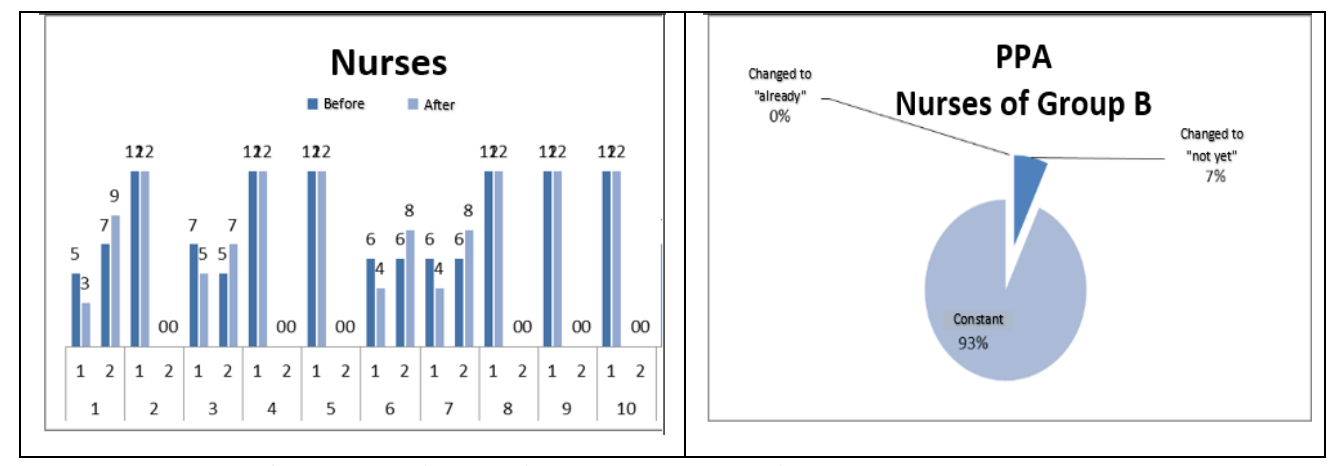

Figure 2. Changed Answer Control Group: PPA Nurses

In the nurses PPA, there are $93 \%$ of patients have a constant opinion and $7 \%$ think they change in being "not yet" in answering the researcher's questions. The dimensions that were assessed as changing were the dimensions of respect for the values, preferences, and needs of patients, the dimensions of continuous care and a smooth transition, the dimensions of communication and education, the dimensions of physical comfort, and the dimensions of the involvement of family and friends.

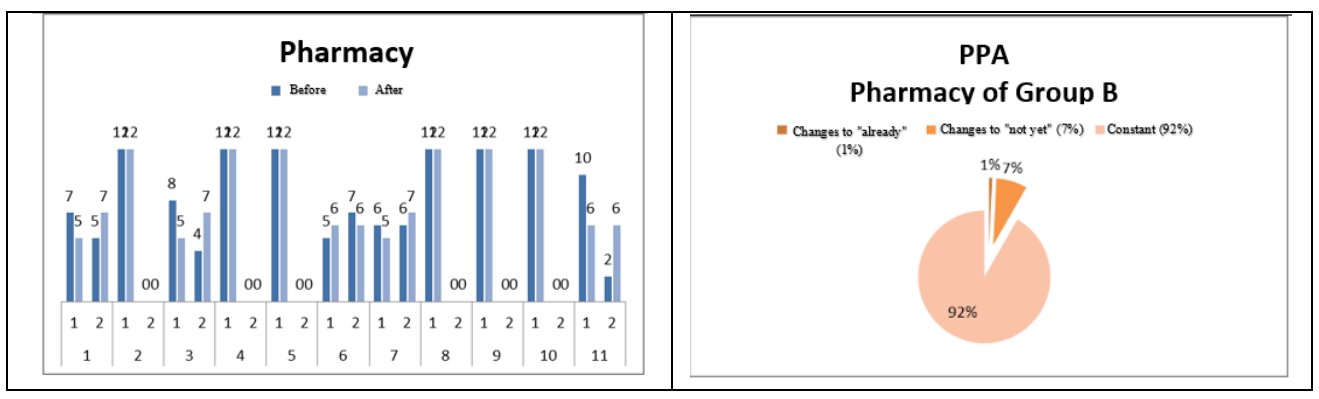

Figure 3. Changed Answer Control Group: PPA Pharmacy

In Pharmacy PPA, there are $92 \%$ of patients think it is constant and $7 \%$ think it changes to "not yet" and $1 \%$ think it changes to "already" in answering the researcher's questions. The dimensions that 
were assessed as changing to "not yet" were the dimensions of respecting the values, preferences, and needs of patients, the dimensions of continuous care and a smooth transition, the dimensions of physical comfort, and the dimensions of access to health services. While the dimensions that have changed towards "already" are the dimensions of communication and education.

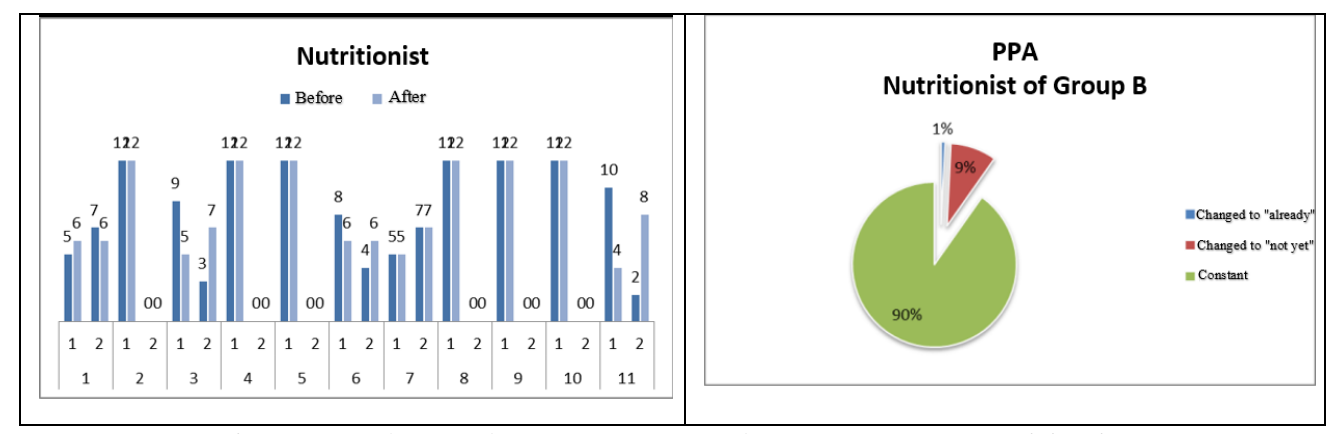

Figure 4. Changed Answer Control Group: PPA Nutritionist

In nutritionist PPA, 90\% of patients thought it was constant and 9\% thought it changed to "not yet" and $1 \%$ thought it changed to "already" in answering the researcher's questions. The dimensions that are considered to have changed to "not yet" are the dimensions of sustainable care and a smooth transition, the dimensions of communication and education, and the dimensions of access to health services. Meanwhile, the dimension that changed towards "already" was the dimension of respecting the patient's values, preferences, and needs.

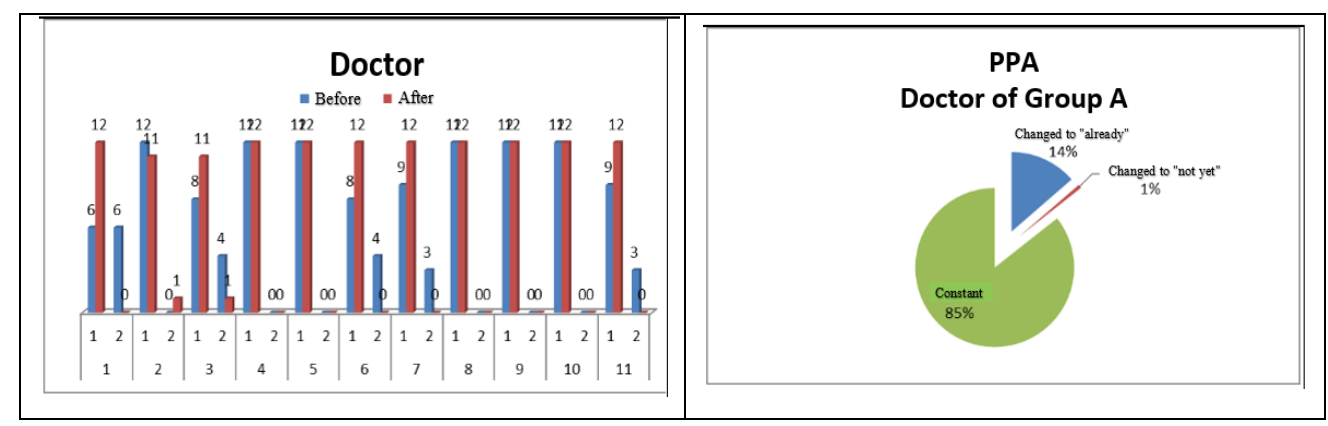

Figure 5. Changed Answer Treatment Group: PPA Doctor

In the doctor's PPA, there are $85 \%$ of patients have a constant opinion and $15 \%$ think that they have changed in responding to an assessment of the doctor's treatment of patients. Of the $15 \%$ change in opinion, $1 \%$ of respondents answered changed to "not yet". The change in the patient's answer was in the dimensions of coordination and integrated care while changing opinions to "already" amounted to $14 \%$ of respondents with the dimensions of respecting patient values, preferences, and needs, continuous care and a smooth transition, communication and education, physical comfort and access. to health services.

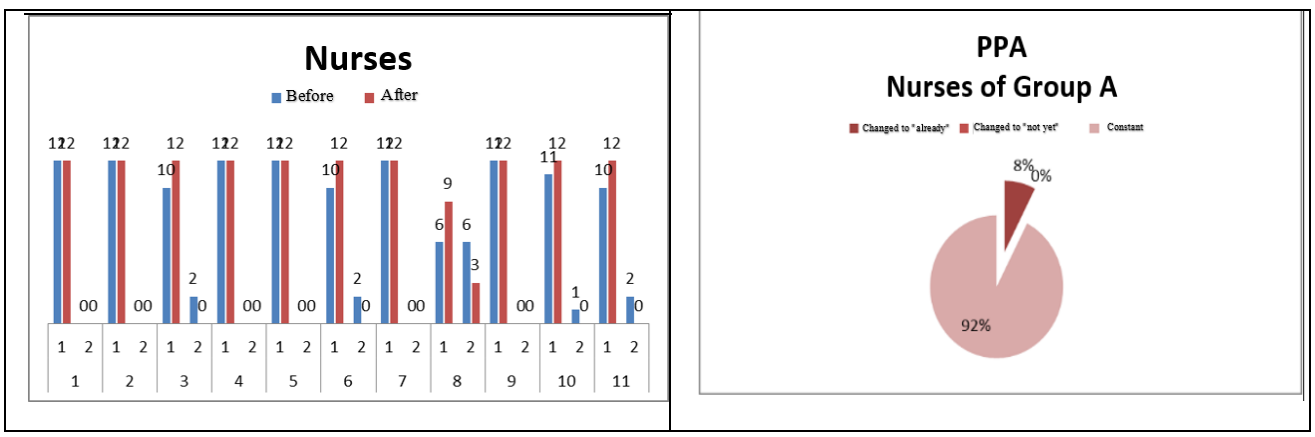

Figure 6. Changed Answer Treatment Group: PPA Nurses 
In nurses PPA, there are $92 \%$ of patients have a constant opinion and $8 \%$ think that they have changed in responding to an assessment of the doctor's treatment of patients. All patients whose answers changed, namely $8 \%$ of respondents answered changed to "already". In the changes in the patient's answers, there are dimensions of continuous care and smooth transition, communication and education, physical comfort, involvement of family and friends, and access to health services.

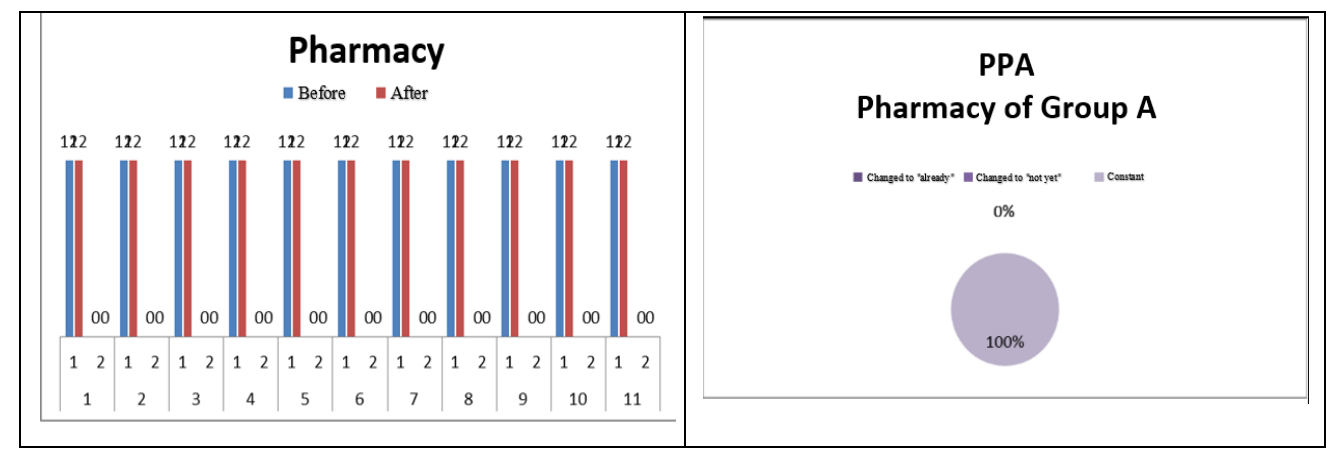

Figure 7. Changed Answer Treatment Group: PPA Pharmacy

In pharmacy PPA, there are $100 \%$ of patients have a constant opinion. This means that the patient's view of the pharmacy on both tests is rated equally across all dimensions of the PCC variable.

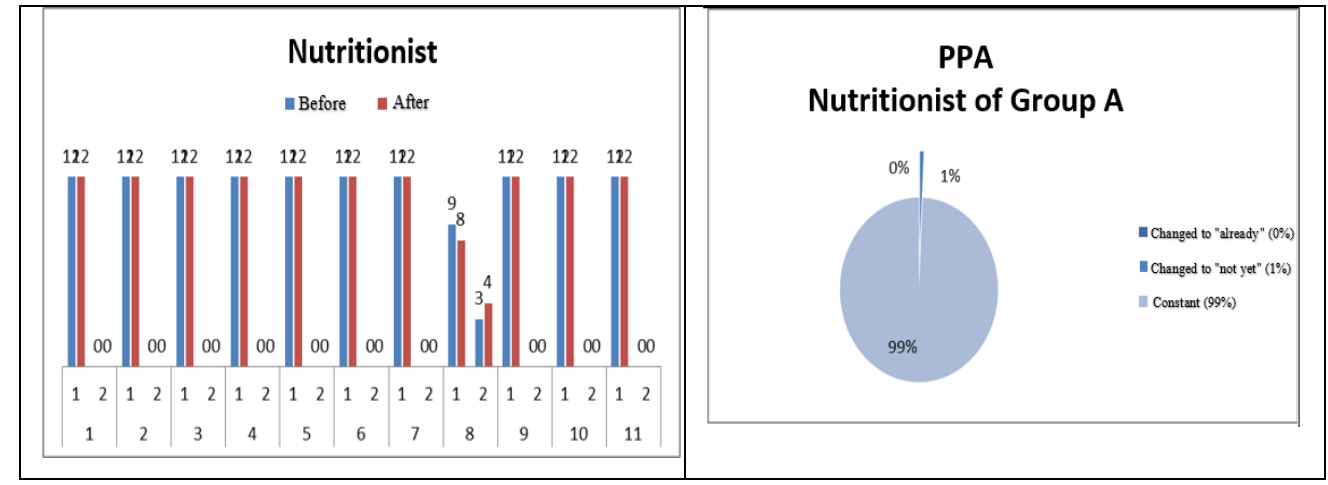

Figure 8. Changed Answer Treatment Group: PPA Nutritionist

In the PPA nutritionist, there are $99 \%$ of patients have a constant opinion and $1 \%$ have a changed opinion in responding to the assessment of nutritional treatment in patients. All patients whose answers changed, namely $1 \%$ of respondents answered changed to "not yet". The change in the patient's answer is in the dimension of physical comfort. Furthermore, the other dimensions can be concluded to be constant or there is no change because $99 \%$ of respondents answered constant or no change.

\section{Bivariate Test Analysis}

Bivariate analysis was used to determine differences in patient perceptions of the intervention group and the control group before and after the implementation of Patient Center Care services in the children's section at a Hospital in Central Java. In this bivariate analysis, the researcher used the T-Test Independent Analysis because the research data were normally distributed. Here are the results of the TTest Independent Analysis:

Table 1.

Result of T-Test Independent Analysis

\begin{tabular}{|l|l|l|}
\hline \multicolumn{2}{|l|}{ Sig. (2-tailed) } \\
\hline Control Treatment & Equal variances assumed & 0.000 \\
\hline & Equal variances not assumed & 0.000 \\
\hline
\end{tabular}


The results of the T-Test Independent Analysis (Table 1) obtained the Asymp value. Sig. (2tailed) of 0.003 , which is less than alpha $(<0.05)$ so that the alternative hypothesis $(\mathrm{H} 1 / \mathrm{Ha})$ is accepted. This study supports the research conducted by Ahenkorah Josephine (2015) where the practice of the PCC approach is important.

\section{Limitation of the Study}

In this study, the overall respondents were children, so that in data collection, parents or family were sometimes represented, which caused the answer not $100 \%$ of the opinion of the children who were respondents because of outside intervention. There is a limited number of Caregiver Professionals (PPA) so that the description of Patient Centered Care (PCC) treatment is still not valid to describe the entire line of PPA in general.

\section{Conclusions and Suggestions}

This study proves that there are differences in patient perceptions in the pediatric section before and after the implementation of PCC in the control group at a Hospital in Central Java and there are differences in patient perceptions in the pediatric section before and after the implementation of PCC in the intervention group at a Hospital in Central Java.

Dimensions of changes that occurred in the treatment group which felt from not being implemented by PPA to PCC were in the dimensions: a) respecting the values, preferences, and needs of patients, b) continuous care and a smooth transition, communication and education, physical comfort, and c) access to health services. while those who feel that PCC has been implemented by PPA to not are in the dimensions of integrated coordination and care. then some dimensions that according to the treatment group did not change were the dimensions: a) information, communication, and education, b) physical comfort, c) emotional support and eliminating fear and anxiety, and d) involvement of family and friends.

The dimensions of the changes that occurred in the control group, which felt that PCC had not been implemented by the PPA already were, were in the dimensions: a) respecting the values, preferences, and needs of patients, and b) continuous care and a smooth transition. Meanwhile, those who feel that PCC has been implemented by PPA to not are in the dimensions of a) communication and education and b) physical comfort. In addition, the dimensions that did not change were a), access to health services, b) involvement of family and friends, c) Information, Communication, and Education, and d) Emotional support and relieving fear and anxiety.

\section{Reference}

Ben Natan, M., n.d. Patient-Centered Care in Healthcare and its Implementation in Nursing. International Journal of Caring Sciences 10, 596.

Gerteis, M., Susan Edgman-Levitan, 1993. What patients really want.

Indonesia, P., n.d. Undang-Undang Republik Indonesia Nomor 44 Tahun 2009 Tentang Rumah Sakit.

Jardien-Baboo, S., Van Rooyen, D., Ricks, E., 2016. Perceptions of patient-centred care at public hospitals in Nelson Mandela Bay. Health SA Gesondheid 21, 397-405. https://doi.org/10.4102/hsag.v21i0.997

Josephine Ahenkorah, Snowdon Nicola, 2015. Perspectives on patient-centred care: a survey of Ghanian physiotherapists. Int J Physiother. 2, 502-512. 
Kharismawati, N.L., n.d. Hubungan Konsep Patient Centered Care Dengan Mutu Pelayanan Kesehatan Di Ruang Rawat Inap Rumah Sakit Bangli Medical Canthi Di Kabupaten Bangli Tahun 2015: 15.

Lintang, C.S., Maramis, J.R., 2019. Pengalaman Perawat Instalasi Gawat Darurat Merawat Pasien Do Not Resuscitate. KJN 1, 40. https://doi.org/10.37771/kjn.v1i1.369

Rachma, A.H., Kamil, H., n.d. Pelaksanaan Patient Centered Care Di Rumah Sakit Umum Kota Banda Aceh :10.

Riskiyah, R., Hariyanti, T., Juhariah, S., 2017. Pengalaman Pasien Rawat Inap terhadap Penerapan Patient Centered Care di RS UMM. Jurnal Kedokteran Brawijaya 29, 358-363. https://doi.org/10.21776/ub.jkb.2017.029.04.13

Rosa, E.M., 2018. Patient Centered Care Di Rumah Sakit Konsep Dan Implementasi. Lp3m.

Skapinakis, P., 2014. Spielberger State-Trait Anxiety Inventory, in: Michalos, A.C. (Ed.), Encyclopedia of Quality of Life and Well-Being Research. Springer Netherlands, Dordrecht, pp. 6261-6264. https://doi.org/10.1007/978-94-007-0753-5_2825

Smith, C., n.d. Patients' Perceptions of Patient-Centered Care and the Hospital Experience Pre-and Post-Discharge: 133.

Suza, D.E., n.d. Family-Centered Care Model untuk Menurunkan Dampak Hospitalisasi Anak dengan Penyakit Kanker di Medan, Sumatera Utara 10.

\section{Copyrights}

Copyright for this article is retained by the author(s), with first publication rights granted to the journal.

This is an open-access article distributed under the terms and conditions of the Creative Commons Attribution license (http://creativecommons.org/licenses/by/4.0/). 